\title{
ANTIMICROBIANOS
}

\section{Nuevas quinolonas: una visión del clínico}

\author{
GUILLERMO ACUÑA L.
}

\begin{abstract}
NEW QUINOLONES: A CLINICAL PERSPECTIVE
A review of the possible indications and advantages of the new generation of quinolones is done with reference to respiratory, bone and soft tissue, intrabdominal and pelvic, central nervous system, and sexually transmitted diseases infections. An especial remark is done in reference of possible important toxic side effects of these new antimicrobials.
\end{abstract}

Key words: Quinolones; New generation; Clinical perspective.

La llegada al mercado de un nuevo grupo de antimicrobianos, hace necesario que el clínico se plantee cuál es el nicho y cuál será la posible contribución de estos nuevos productos al armamentario farmacológico.

No existe clara coincidencia entre la evolución de nuevos productos por parte de la industria farmacéutica y las necesidades de dichos productos en la comunidad de un determinado país o en diferentes regiones de un mismo país.

La próxima entrada al mercado de nuevos productos quinolónicos, y el retiro temprano de comercialización por efectos adversos severos (temafloxacina, trovafoxacina, grepafloxacina, sparfloxacina) obliga al médico a analizar los aspectos positivos y negativos de estas adiciones.

\section{¿Qué podemos esperar de las nuevas quinolonas?}

\section{Infecciones respiratorias}

Este es el campo de mayor interés para la industria farmacéutica dado que el mercado en unidades y valores muestra que es una importante área de negocios.

Se ha puesto en duda la efectividad de ciprofloxacina en la cobertura de estreptococos, en especial Streptococcus pneumoniae lo que, si bien es controversial, refleja la opinión de la mayoría de los especialistas en neumología e infectología. Este punto ha podido superarse con levofloxacina, isómero levógiro de ofloxacina, la cual de por sí había demostrado una mejor actividad anti Gram positivos que ciprofloxacina. Los nuevos productos grepafloxacina, trovafloxacina, sparfloxacina, moxifloxacina, gemifloxacina, clinafloxacina y gatifloxacina, presentan una importante mayor actividad sobre estreptococos en comparación con ciprofloxacina. Sin embargo los efectos tóxicos reportados con el uso de trovafloxacina, sparfloxacina y últimamente grepafloxacina, han hecho que ninguno de estos productos (pre aprobados por el ISP) sea comercializado en nuestro país. Nos quedamos por el momento con levofloxacina y a la espera de lo que suceda

\footnotetext{
${ }^{1}$ Departamento de Medicina. Pontificia Universidad Católica de Chile. Asociación Chilena de Seguridad y Clínica Las Condes
} 
con moxifloxacina y los otros productos nombrados.

El otro avance importante en esta área es la actividad de las quinolonas sobre los llamados microorganismos atípicos (Legionella spp, Mycoplasma spp, Chlamydia spp), lo que permite usar estos productos con la seguridad de una cobertura sobre Streptococcus spp, Haemophilus influenzae, Moraxella catarrhalis, y los ya nombrados "atípicos"

La muy buena biodisponibilidad de las quinolonas significa contar con un producto potente que permite su administración oral o el fácil paso de una formulación parenteral a oral, y la posibilidad de completar el tratamiento en el domicilio del paciente con los beneficios de calidad de vida y económicos que esto representa.

A la favorable biodisponibilidad hay que agregar los buenos niveles tisulares alcanzados en pulmón, bronquios, oído medio y senos paranasales.

En conclusión, en el campo de las infecciones respiratorias bacterianas, las nuevas quinolonas deberán constituirse en alternativas de mucho valor para su tratamiento. A lo anteriormente nombrado hay que destacar la actividad de alguna de ellas sobre especies anaerobias (moxifloxacina, trovafloxacina, clinafloxacina), lo que permitirá manejar las infecciones respiratorias con monoterapia y eventualmente con dosis únicas diarias.

La actividad sobre micobacterias es un campo donde aún las quinolonas deberán ser evaluadas mayormente.

\section{Infecciones intrabdominales y pelvianas}

En el caso de infecciones con flora mixta, un producto que cubra especies Gram negativas aerobias y facultativas además de anaerobias estrictas, es de gran interés. En especial, contar con antimicrobianos que puedan emplearse por vía parenteral inicialmente, mientras el tubo digestivo no esté funcionante, para luego proseguir por vía oral sin sacrificar potencia ni niveles, es de gran interés. Debiera permitir también en el área de costo/ efectividad, trasladar anticipadamente a un paciente de una unidad crítica a sala y luego a su domicilio.
El posible efecto sobre el desarrollo del esqueleto fetal obliga a sopesar adecuadamente su prescripción en infecciones obstétricas o en mujeres potencialmente embarazadas.

\section{Infecciones de huesos y tejidos blandos}

Uno de los problemas difíciles de manejar es el pie diabético infectado. Nos encontramos en una situación de infección causada por flora mixta, en un territorio mal irrigado, que requiere de un manejo médico-quirúrgico en muchas oportunidades y ante el cual el tratamiento antimicrobiano debe prolongarse por varias semanas o meses. Actualmente debemos recurrir a una combinación de antimicrobianos, algunos de los cuales sólo alcanzan concentraciones plasmáticas adecuadas en altas dosis administradas por vía endovenosa. A pesar de que los ensayos clínicos en esta área son aún limitados en número, hay reportes auspiciosos y puede ser esta un área en que esos nuevos productos sean un real aporte.

En osteomielitis, su uso sigue siendo limitado a las etiologías por bacilos Gram negativos, incluyendo Salmonella spp, pero su actividad anti estafilocóccica no ha mejorado suficientemente para tratar este tipo de etiología, menos en los casos de SAMR.

Otras infecciones con etiología mixta, como la infección de escaras de decúbito, infecciones en deforramiento de extremidades, etc., también se verán beneficiadas con la disponibilidad de estos productos.

\section{Infecciones del sistema nervioso central}

Gran expectativa se había forjado con el uso de trovafloxacina en infecciones del SNC, en especial en meningitis por $S$. pneumoniae resistente a penicilina y cefalosporinas. El retiro parcial del producto en EE.UU. y el muy probable no ingreso del producto al mercado chileno, nos dejará probablemente sin esta alternativa terapéutica que pudiera ser importante en el futuro.

\section{Infecciones de la via urinaria}

En infecciones urinarias no complicadas las 
nuevas quinolonas no ofrecen ventajas importantes en relación a lo ya existente. Por una parte su actividad anti bacilos Gram negativos no supera a la de ciprofloxacina siendo, en general, menor en el caso de Pseudomonas spp. Sólo la posibilidad de dosificar una vez al día pudiera constituirse en una ventaja relativa (ya presente en fleroxacina y levofloxacina). En principio parece poco adecuado el uso en esta indicación.

\section{Enfermedades de transmisión sexual}

Tampoco hay en este campo factores que determinen ventajas de estos nuevos productos en el área, es posible usar dosis única en infecciones causadas por Neisseria gonorrhoeae pero no ante Chlamydia sp o Ureaplasma $s p$.

\section{CONCLUSION}

Las nuevas quinolonas, son productos de gran interés y posible valor en algunas áreas de las infecciones bacterianas. Su principal aporte es la potente actividad anti estreptocóccica incluyendo $S$. pneumoniae resistente a $\beta$-lactámicos (penicilina y cefalosporinas) y manteniendo buena actividad sobre patógenos Gram negativos. Algunos de los nuevos productos presentan además una interesante actividad anti anaerobia. Sus interesantes propiedades farmacológicas permitirán simplificar algunos tratamientos adaptándose a las necesidades actuales de disminuir los días de hospitalización y favoreciendo el tratamiento ambulatorio.

La comprobación de severos efectos adversos, que aunque infrecuentes, han obligado al retiro o limitación en el uso de algunos de estos compuestos, obligan a los médicos ha tener una gran preocupación en el empleo masivo de estos nuevos productos.

\section{RESUMEN}

Se efectúa una revisión de las posibles indicaciones y ventajas de la nueva generación de quinolonas con relación a infecciones respiratorias, óseas y de tejidos blandos, intraabdominales y pélvicas, del sistema nervioso central y enfermedades de transmisión sexual.

Se hace una especial advertencia sobre los posibles efectos tóxicos secundarios de estos nuevos antimicrobianos.

Correspondencia a:

Guillermo Acuña Leiva

Email: gacuna@netline.cl 